\title{
Нижегородцева Н.А. \\ Особенности учебной деятельности студентов в процессе становления цифрового общества
}

Северо-Западный институт управления - филиал Российской академии народного хозяйства и государственной службы при Президенте РФ

(Россия, Санкт-Петербург)

doi: 10.18411/trnio-12-2021-240

\section{Аннотация}

Статья посвящена исследованию проблемы учебной деятельности студентов в период самоизоляции в дистанционном формате обучения. Отмечаются положительные стороны цифровых, онлайн технологий обучения при переходе к цифровизации образования как необходимом условии подготовки современных кадров цифровой эпохи. Раскрываются риски отрицательного результата внедрения полной цифровизации общества в целом и цифровизации всей системы образования, которая предполагает снижение личных контактов студентов и преподавателей, общения студентов в учебных группах, что создает проблему социализации молодых людей, в чем проявилось их видение и понимание заявленной проблемы. Подчеркивается использование цифровых технологий только в качестве средства во взаимной деятельности студентов и преподавателей, необходимость разработки адекватной психолого-педагогической теории, органично включающей в себя компьютер как средство обучения с его возможностями получения, хранения, переработки и передачи информации. Обосновывается позиция, что в качестве научной основы цифровизации обучения, способна стать психолого-педагогическая теория контекстного образования Вербицкого А.А.

Ключевые слова: цифровизация образования, цифровые технологии, учебная деятельность студентов, информация, знание, воспитание, контекстное образование, цифровое обучение, цифровая система образования, диалог.

\section{Abstract}

The article is devoted to the study of the problem of educational activity of students during the period of self-isolation in a distance learning format. The positive aspects of digital, online learning technologies are noted in the transition to digitalization of education as a necessary condition for training modern personnel in the digital era. The risks of a negative result of the introduction of complete digitalization of society as a whole and the digitalization of the entire education system are revealed, which involves a decrease in personal contacts between students and teachers, communication of students in study groups, which creates the problem of socialization of young people, which manifested their vision and understanding of the stated problem. The author emphasizes the use of digital technologies only as a means in the mutual activities of students and teachers, the need to develop an adequate psychological and pedagogical theory that organically includes a computer as a teaching tool with its capabilities for receiving, storing, processing and transmitting information. The position is substantiated that the psychological and pedagogical theory of contextual education by A.A. Verbitsky can become the scientific basis for the digitalization of education.

Keywords: digitalization of education, digital technologies, educational activities of students, information, knowledge, upbringing, contextual education, digital learning, digital education system, dialogue.

Ведущие специалисты в области педагогики, психологии, философии, социологии обозначают фундаментальность происходящих изменений как период больших возможностей и потенциальных опасностей, при этом одну из ключевых областей, порождающих целый спектр разнообразных рисков, считают Российскую систему 
образования. Исследователи предполагают, что революционные изменения в организации образовательного процесса в высшей школе возможны только на основе разработки новых компетентностей, соответствующих цифровой экономике [15].

Многие исследователи отмечают положительные стороны цифровых, онлайн технологий обучения, рассматривая переход к цифровизации образования как необходимое условие подготовки современных кадров цифровой эпохи. При этом цифровая образовательная среда рассматривается как огромный педагогический потенциал для формирования цифровой грамотности, цифровой компетенции и самостоятельности студентов в информационном онлайн-мире $[1 ; 13]$.

Ресурс человека как индивида, вовлеченного в процессы цифровизации, нами увязывается с повышением доступности ему информации, доставляемой с использованием соответствующих новых технологий. Доступность информации обнаруживается по темпоральным показателям (экономия времени получения нужных сведений вне зависимости от локации их источника и реципиента), форме представления (аудиальная, визуальная, статическая, динамическая, графическая, объемная вариабельность), объему, структуре и содержанию (извлечение любого интересующего фрагмента, возможность ускоренного просмотра). Благодаря процессам цифровизации расширяется доступ человека к информации, ранее ограниченный обременительностью ее прямого получения. Внедрение новых информационных технологий позволяет человеку перевести свою деятельность на уровень, ранее не свойственный ей по качеству и скорости, всесторонне преобразовать ее на этапах подготовки, выполнения и итогового анализа. Соответственно, основным ресурсом человека как субъекта, включенного в процессы цифровизации, мы видим достижение им нового качества условий, процесса и результатов своей деятельности на основе использования новых информационных технологий.

Информатизация сферы образования играет важную роль в повышении качества и доступности образования. Внедрение новых технологий в процесс обучения позволяет наряду с традиционными учебными материалами использовать современные электронные средства поддержки и сопровождения образовательного процесса. Однако помимо преимуществ, существуют и угрозы, которые вызваны организацией единой цифровой образовательной среды, и их нельзя игнорировать. При внедрении данной системы необходимо тщательно оценить последствия цифровизации обучения и принять оптимальную стратегию защиты от вызываемых ею угроз.

Вместе с тем, есть мнения о риске отрицательного результата внедрения полной цифровизации общества в целом и цифровизации всей системы образования, которая предполагает снижение личных контактов студентов и преподавателей, общения студентов в учебных группах, что создает проблему социализации молодых людей.

Поколение для современной психологии - это уже не просто общность родившихся в определённый год людей. Психологи давно поняли, что каждое поколение несёт в себе уникальный исторический и культурологический опыт, который не повторится у другой поколенческой когорты. Именно это заставило исследователей давать поколениям имена. Например, миллениалы, беби-бумеры, поколения X, Y, Z.

По мнению психолога Юрия Зинченко, каждое поколение несёт в себе уникальный исторический и культурологический опыт.

Так называемая теория поколений далеко не безупречна, тем не менее от названия конкретного поколения не меняется главное: поколенческие группы различаются своими ценностями, привычками, социальными установками. «Виной» тому — их культурный, исторический и социально-психологический бэкграунд.

Многим исследователям интересно современное молодое поколение Z (самым старшим его представителям сейчас 18-20 лет). Это логично: именно это поколение сейчас учится в университетах, а значит, скоро займёт рабочие места, начнёт голосовать на выборах, войдёт в активную потребительскую фазу. В качестве ключевых черт 
представителей поколения вспоминают их погружённость в мир интернета: неслучайно их метафорично называют цифровыми аборигенами.

Часто поколение Z называют более свободным. Оно не торопится использовать классические критерии взросления более старших поколений. Нам ещё предстоит глубже познать это поколение, но уже сейчас понятно, насколько интересным и ярким может быть взаимодействие с ним. Нам есть чему у него поучиться.

Суммируя в самом общем виде существующие точки зрения, можно выделить две позиции: 1) онлайн-образование в эпоху пандемии выявило свою насущную необходимость и будет все больше и больше развиваться, постепенно заменяя образование офлайн; 2) онлайн-образование никогда не заменит офлайн и останется «вспомоществованием» к традиционному университетскому образованию.

Во-первых, введенное в начале 2020 года экстренное дистанционное обучение при помощи интернет-технологий — это не то же самое, что онлайн-образование. Термины «удаленный», «дистанционный» и «онлайн-образование» использовались и сегодня продолжают использоваться как синонимы для характеристики практик организации обучения в университетах и в средних школах. К сожалению, подобная синонимизация проявляется как подмена понятий и, уж точно, не помогает понять происходящее сегодня в образовании.

Суть дела в том, что экстренно/неотложно введенное дистанционное обучение с помощью интернет-платформ не представляет собой тип или подвид «онлайн-образования». «Экстренное дистанционное обучение» было введено вследствие «служебной необходимости» и изначально предполагалось как реакция на кризисную ситуацию, в которой находилось образование в связи с развитием COVID-19 во всем мире. Это временная мера, которая позволила с определенными потерями, но все-таки продолжить образовательный процесс. Преподаватели, которые организовывали и вели свои курсы как «живое общение» со студентами в аудитории, вынуждены были срочно перестроиться и адаптировать образовательный процесс к новым неожиданным обстоятельствам. Причем от преподавателей и студентов требовали такого же качества организации и проведения образовательного процесса. Такие требования, мягко скажем, были некорректны. И дело не только в неподготовленности обеих сторон к новым экстренным практикам, и не только в возможностях технологий [12].

Во-первых, онлайн-образование - это специально организованные образовательные практики, тщательно (специально) продуманный дизайн взаимодействий субъектов обучения с использованием методик и технологий, изначально предназначенных для существования в онлайн-среде.

Во-вторых, социологи у нас в стране и особенно за рубежом активно обсуждали проблему «Digital Divide» (в переводе с англ. электронно-цифровой разрыв, цифровое неравенство, цифровая пропасть, цифровой барьер). Ситуация с заменой классического образования как живого общения профессора и студента на обмен информации между «источником» и «получателем» как минимум переоценивает одинаковость способности людей взаимодействовать с цифровыми технологиями не были готовы к тому, как будут реагировать участники образования (и в первую очередь студенты) на плохой доступ к интернету (или отсутствие подключения к интернету), отсутствие доступа к веб-камерам, ноутбукам и т.д. Но изначальная посылка введения «экстренного дистанционного образования с помощью интернета» состояла в том, что преподавательский состав, возможно, будет не очень готов переходить к интернет-взаимодействиям, но учащиеся полностью примут цифровые технологии и преуспеют в дистанционных практиках, не учитывая существенных различий в индивидуальном опыте и среде.

В-третьих, введение любой «экстренно дистанционной формы обучения» или специального «онлайн-образования» никогда не сможет заменить принципиально важные для образования вещи - то, что дает только «живое общение» - эмоциональные связи по 
трем направлениям: преподаватель - студент; студент - студент; преподаватель преподаватель/научный руководитель.

Все три проблемы, по сути дела, связаны с некритическим переносом положений математической (технической) теории коммуникации на анализ взаимодействий людей. «Онлайн» как совокупность каналов и, шире, технических средств коммуникации должно быть далее осмыслено по трем направлениям. 1) Средства могут быть по-разному организованы и лучше или хуже подготовлены к использованию в конкретных ситуациях и социальных контекстах. 2) Технологии - не пассивный посредник коммуникации, но потенциальный агент взаимодействия. Иными словами, чтобы начать или продолжить коммуникацию с человеком, мы все чаще вынуждены взаимодействовать с технологиями. Развитие искусственного интеллекта, разумеется, переводит данную проблему на новый уровень 3) Коммуникация не есть общение: в том, что происходит между людьми, лишь немногое может быть напрямую оцифровано, переведено в биты информации. А многое оцифровке «сопротивляется», поддается лишь с трудом.

Мы неслучайно начали рассуждения о месте и роли социальных наук в осмыслении проблем цифровой трансформации и внедрения технологий искусственного интеллекта в повседневность с необходимости проведения принципиальных различий между «онлайнобразованием» и «экстренным дистанционным обучением».

Обращаясь к данным опросов, мы можем зафиксировать этот разрыв в виде противоречия между негативной оценкой существующих практик и позитивной оценкой возможностей, возникающих в новых условиях [12].

С одной стороны, полный переход на дистанционное образование вызывает, скорее, отторжение. В августе 2020 года 68 \% тех, у кого есть дети или внуки школьного возраста, полагали, что в онлайн-обучении больше минусов, чем плюсов, и 74 \% считали, что переход на дистанционный формат в их школе снизил бы качество обучения. Конкретные временные - практики перехода на дистанционное обучение вызывают неоднозначное отношение. Так, в мае 2020 года организацией дистанционного образования в конкретном учебном заведении были удовлетворены $44 \%$ родителей выпускников, $72 \%$ студентов вузов и 74 \% студентов техникумов. (Заметим, что процент довольных повышается с переходом от обязательного школьного образования к более гибко организованному высшему и среднему.) Сходная картина наблюдается в отношении удаленной работы. Из тех, кто перешел «на удаленку» в период пандемии или работал удаленно до того, в апреле 2020 года такой режим нравился лишь $36 \%$ ответивших.

С другой стороны, «онлайн» - в позитивном смысле - понимается как расширение возможностей, а не как замещение одних активностей другими. Этот банальный тезис нашел подтверждение в период пандемии. В апреле 2020 года ВЦИОМ провел исследование, в рамках которого задавался вопрос: «Что, по Вашему мнению, из появившегося в нашей жизни во время коронавирусной эпидемии нужно сохранить после ее окончания?» Возможность онлайн-образования в вузах - $30 \%$ опрошенных. Этот показатель соответствует и результатам, полученным в нашем исследовании, а именно: вопрос о соотношении очного и дистанционного обучения - 70 \% к 30 \%, соответственно, - $31 \%$ участвующих в опросе студентов СЗИУ.

Целью нашего исследования являлось изучение влияния цифровых технологий (ЦТ) на особенности учебной деятельности студентов.

За основу были взяты исследования психологов, педагогов, философов, социологов вузов Российской Федерации: Удмуртский университет, Бурятский государственный университет (Улан-Удэ), Северо-Восточный университет им. М.К. Аммосова (Якутск), Норильский индустриальный институт, РГПУ им. А.И. Герцена (Санкт-Петербург); СЗИУ PAНХ и ГС (Санкт-Петербург), Самарский государственный технический университет, Орловский государственный университет, Московский городской педагогический университет, Институт психологии РАН, кафедра общей психологии МГУ, Московский Гуманитарный университет, Санкт-Петербургский национальный исследовательский 
университет информационных технологий, механики и оптики (Университет ИТМО), Корпоративный университет Сбербанка, факультета психологии МГУ, факультет социологии СПбГУ, Уфимский государственный нефтяной технический ун-т, Ивановский государственный университет, Петрозаводский государственный университет, Волгоградский технический университет и др., а также ВЦИОМ.

Изучался, анализировался, обобщался и систематизировался материал проведенных исследований различных аспектов влияния ЦТ на образовательный процесс.

Для того чтобы выявить реперные точки в понимании студентами особенностей влияния ЦТ на учебную деятельность в современных условиях, им было дано задание сформулировать вопросы анкеты и провести опрос студентов. Перечень и формулировки вопросов с вариантами ответов показали, как студенты видят основные проблемы цифровизации общества, участниками которой они являются.

Первая задача исследования состояла в анализе цели и продолжительности использования студентами цифровых технологий.

Результаты анкетирования показали, что $87 \%$ студентов проводят в Сети более 6 часов, а 13\% - более 3 часов, т.е. все студенты используют сети интернет.

Интересны результаты о цели использования интернета. 83\% времени студенты тратят на просмотр видео и фильмов, общение, учебную деятельность; 74\% - на отдых и развлечения; 70\% - просмотр новостей и покупку товаров и услуг; 35\% - чтение книг. Мы видим, что сегодняшняя студенческая молодежь активно и свободно владеет цифровыми технологиями и использует их в своей жизни.

При этом 63\% студентов ощущают перегруженность информационным шумом и $30 \%$ осознают, что тратят на пребывание в сетях слишком много времени, т.е. 93\% опрошенных. Можно предположить, что такая перегруженность способствует эмоциональному выгоранию, снижает стрессоустойчивость и эффективность протекания всех психических процессов, что подтверждают исследования в области психологии, физиологии, медицины. И только 7\% студентов считают, что проводят в сетях достаточное для них количество времени.

Вторая задача была посвящена исследованию влияния цифровых технологий на учебную деятельность студентов.

Результаты показали, что $61 \%$ студентов отдают предпочтение нахождения информации в интернете; $28 \%$ - в учебных и научных изданиях; библиотечным фондом пользуется 9\% и читальным залом - $2 \%$ респондентов. $43 \%$ студентов считают, что применение ЦТ позволяет им повысить качество учебной деятельности; 39\% - значительно повысить. Однако 15\% студентов осознают, что использование ЦТ позволяет им хорошо учиться, но результаты формальные по БРС, т.е. качество учебной деятельности не улучшается. И 3\% респондентов не осознают влияния ЦТ на их учебную деятельность.

Мнения студентов об отрицательном влиянии ЦТ на учебную деятельность распределились следующим образом. 64\% испытуемых не считают, что применение ЦТ оказывают отрицательное влияние на их учебную деятельность; $18 \%$ - считают, что ЦТ отнимают много времени, которое они могли бы посвятить учебе. Такой же показатель - $18 \%$ респондентов - осознают, что ЦТ негативно отражаются на учебной деятельности: они стали хуже учиться, отвлекаются, фрагментарно мыслят, основательно не вникают в изучаемые вопросы, т.е. в сумме это более $36 \%$ опрошенных студентов.

Насколько студенты полагаются на цифровые технологии в процессе обучения, получены следующие результаты. 56\% респондентов полагаются на ЦТ, т.к. им необходимо получать информацию для успешной учебной деятельности. При этом 28\% опрошенных осознают, что слишком полагаются на ЦТ, но при этом не получают глубокие знания, а только ретранслируют полученную информацию. Полагаем, что в данном мнении студентов кроется проблема формальной мотивации успешной учебной деятельности. И только 16\% испытуемых не полагаются на ЦТ и используют их как вспомогательное средство в своей учебной деятельности. 
Немало важным является вопрос об учебной нагрузке на студентов во время дистанционного обучения. 46\% респондентов затруднились ответить, увеличилась или уменьшилась на них учебная нагрузка. $23 \%$ опрошенных считают, что учебная нагрузка, в целом, увеличилась; 19\% отметили, что она уменьшилась, а $12 \%$ считают, что она не изменилась. Эти показатели подтверждаются количеством времени, которое студенты уделяют выполнению домашнего задания, а именно: 77\% опрошенных на выполнение домашнего задания тратят более двух часов; $15 \%$ - более трех часов и только $8 \%$ - более 5 часов. Возникает вопрос: как можно получать именно знания по нескольким дисциплинам семестра в среднем за 2-3 часа. Такие результаты не подтвердили нашей гипотезы, что в период дистанционного обучения учебная нагрузка, в целом, на студентов увеличилась.

$46 \%$ респондентов считают, что использование преподавателями ЦТ в процессе обучения позволило бы обучающимся учиться в удобное для них время. 31\% опрошенных, наоборот, ощущают, что и так большое количество времени они проводят в сетях, поэтому не хотят и учебное время тратить на них. 19\% студентов считают, что с применением ЦТ обучение станет более интересным; 8\% испытуемых полагают, что применение ЦТ приведет к большей загруженности домашними заданиями.

Обоюдное применение цифровых технологий преподавателями и студентами происходит в совместной деятельности, носит двусторонний характер. Поэтому интересен был ответ на вопрос, как применение ЦТ преподавателями отразилось на успешности учебной деятельности в период самоизоляции. По результатам анкетирования, 42\% опрошенных оценили формат дистанционного обучения положительно и считают, что он повысил успеваемость в освоении учебных дисциплин. $27 \%$ респондентов осознают, что дистанционное обучение лишь формально влияет на успешность результатов обучения по БРС (балльно-рейтинговой системе), и столько же - $27 \%$ - считают, что дистанционное обучение носит формальный характер, а именно: выполняет преимущественно информационную функцию и не обеспечивает получение знаний и выработку умений. Таким образом, о формальной стороне дистанта высказывается 54\% студентов, принявших участие в исследовании. А 4\% опрошенных констатируют, что время обучения в дистанционном формате было ими потеряно в процессе приобретения профессиональных знаний и умений, и столько же - 4\% - разочаровались в учебной деятельности в формате дистанта. Следовательно, $62 \%$ опрошенных студентов негативно восприняли формат дистанционного обучения.

Логичным было сформулировать вопрос о переходе на полное дистанционное обучение в нашем вузе. $48 \%$ студентов затруднились ответить на этот вопрос; $26 \%$ опрошенных относятся к переходу на полное дистанционное обучение как положительно, так и отрицательно, что не подтвердило наши ожидания.

Конкретизируя предыдущий вопрос, мы решили узнать мнение студентов о соотношении использования дистанционного и очного формата обучения. $31 \%$ респондентов считают, что должно быть 70\% очного и $30 \%$ дистанционного обучения; столько же - $30 \%$ респондентов - считают, что соотношение должно быть $50 \%$ на $50 \%$ очной и дистанционной форм обучения. $15 \%$ опрошенных высказались, что очного обучения должно быть $80 \%$, а дистанционного - $20 \%$. Около $4 \%$ респондентов полагают, что очного формата должно быть $30 \%$, дистанционного $70 \%$; и столько же - в соотношении $20 \%$ - очного и $80 \%$ дистанционного формата.

Вместе с тем, результаты исследования позволили на более глубоком уровне выявить отношение студентов к цифровизации учебной деятельности. Групповое обсуждение во время семинарских занятий выявило, что отношение к дистанционному формату обучения носит неоднозначный характер. Половина опрошенных склонна рассматривать цифровизацию, с точки зрения, успешности учебной деятельности. Другие обращают внимание на негативные аспекты, связанные с формализацией образования, уменьшением доли живого общения как в своей учебной группе и студентами вуза, так и с преподавателями. 
В процессе периода дистанционного обучения, используя различные цифровые методы, платформы TEAMS, ZOOM, электронной почты и др. в различных формах: на лекциях, семинарах, практических занятиях, консультациях, зачетах, экзаменах, защитах курсовых и дипломных работ, практик, обнаружилась тенденция, что студенты, в основном, выступают «ретрансляторами» найденной ими информации в интернете. Однако привести пример для иллюстрации понимания теоретической информации, ответить на уточняющий вопрос, выявить причинно-следственные связи между обсуждаемыми явлениями или процессами, вспомнить и применить ранее изученные понятия им сложно. «Зависает» пауза, тишина, во время которой, думается, судорожно ищется ответ на вопрос в поисковых системах. Следовательно, подготовленные студентами презентации и чтение скачанного из интернета текста своего выступления по теме не конвертируются в знания, не выстраивается система понятого материала, что свидетельствует о не работающем критическом мышлении, формальном, прагматическом подходе к учебной деятельности. За свое участие в работе учебного занятия студентов волнует итог - полученные баллы по системе БРС. В результате, мы оказываемся в ситуации противоречия между жестким ограничением во времени, отведенном учебным планом на занятие, и программой содержания каждой конкретной дисциплины, превращая всю профессиональную подготовку специалистов в формализованный процесс. Необходимо научить студентов (если они не были этому научены в школе) критически осмысливать любую информацию и только после этого приступать к выполнению задачи и поиску новой информации в интернете, развивая критическое мышление.

Добывание информации, а не знаний, имеет вероятность негативных изменений, уход от фундаментальности знаний, снижение личностных и профессиональных компетенций и интеллекта специалистов. Информация и знание - разные понятия: информация - это семиотическая, знаковая система, носитель значений (знаки языка, тексты, звуки речи и т.п.), а знание - подструктура личности, нечто субъективное, личностные смыслы, которые часто бывают разными для разных людей, воспринимающих одну и ту же информацию. Компьютер, в принципе, не способен превращать значения в смыслы, информацию в знание. Это означает, что «компьютерная метафора» - не более, чем метафора; переработка информации компьютером не является механизмом порождения из неё знаний человеком, и нужно искать собственно психологические закономерности и механизмы понимания этого процесса [16].

Разделяя научно обоснованную позицию Вербицкого В.А. и его команды школы контекстного образования, правомерно использовать термины «цифровая система образования», «цифровое обучение» и «цифровая дидактика», поскольку компьютер «не занимается» воспитанием обучающихся. Цифровая дидактика - теория цифрового обучения о закономерностях, принципах и механизмах усвоения обучающимися предметных знаний, умений, навыков, компетенций, в том числе, с использованием компьютера [4].

Наряду с огромными и ещё малоизученными возможностями цифрового обучения можно назвать целый ряд проблем и рисков, связанных с их тотальным внедрением в систему образования.

1. В мире нет педагогической или психолого-педагогической теории цифрового обучения, на которую могли бы опираться школьные учителя, преподаватели колледжей и вузов при его проектировании и использовании. Как нет и убедительных доказательств повышения качества образования посредством использования цифрового обучения. По этой причине существует сознательное или неосознанное сопротивление цифровизации обучения значительной части педагогического корпуса страны, особенно среди учителей и преподавателей старшего поколения.

2. Существует реальный риск деградации речи, а вместе с ней и мышления, поскольку оно совершается в речи, которая в цифровом обучении редуцируется до нажатия пользователем на буквы клавиатуры 
компьютера. Как отмечают исследователи, у детей цифрового поколения мысли фрагментарны, а суждения поверхностны. А уж грамотность детей цифрового поколения просто ужасает. Если школьник или студент не имеет развитой практики живого общения, формирования и формулирования мысли в речи, у него, как показывают психологические исследования, мышление не формируется [7].

А в процессе цифрового обучения живая речь школьника и студента - средство формирования и формулирования мыслей - выключена, по определению. Поэтому, если пойти по пути тотальной индивидуализации обучения с помощью персональных компьютеров, можно прийти к тому, что будет упущена сама возможность формирования творческого мышления, которое по своему происхождению диалогично. Работа человека с компьютером осуществляется в диалоговом режиме. Однако взаимодействие с машиной не является диалогом по своему внутреннему содержанию. Диалог - это развитие темы, позиции, точки зрения совместными усилиями двух и более людей, находящихся во взаимодействии и общении по поводу определённого, неизвестного в тех или иных деталях содержания.

Есть и другая опасность: свёртывание социальных контактов, сокращение практики социального взаимодействия и общения, что приводит к индивидуализму и одиночеству.

3. В цифровом обучении речь вообще не идет о воспитании, тогда как вместе с обучением они должны составлять две стороны одной «медали» образования. Воспитание предполагает «социальную ситуацию развития» (Л.С. Выготский), общение и межличностное взаимодействие субъектов образовательного процесса, эмоционально-ценностное отношение к ситуациям нравственного выбора, проживание и переживание ими этих ситуаций на основе знания принятых в обществе моральных норм [9].

Различение в системе образования выделил еще Платон в диалоге «Софист», призывая отличать от искусства «обучать» искусство «воспитывать», а в «Законах» утверждал, что самым важным в обучении признается надлежащее воспитание.

Основоположник отечественной педагогической психологии Петр Федорович Каптерев подчеркивал, что педагогический процесс - это единство биологического и социального в процессе развития ребенка, человека, построение системы воспитания на фундаменте тщательного изучения целостной природы человека [10]. И основополагающую роль в этом двуедином процессе он отводил именно учителю, педагогу: «Важно не то, чему и как учат, а кто учит». И эта проблема коснулась учебных планов многих вузов, из которых исчезла дисциплина «Педагогика».

Вот и ректор Высшей школы экономики Я.И. Кузьминов предложил тотально перейти на онлайн-обучение в вузах, заменив всех профессоров и доцентов персональными компьютерами.

Сказанное отнюдь не означает, что не следует использовать цифровое обучение, как раз, наоборот. Но важно «не пересолить», важно найти психологически, физиологически, педагогически и методически обоснованный баланс между использованием возможностей компьютера и живым диалогическим общением субъектов образовательного процесса педагога и обучающихся.

Цифровые обучающие устройства являются воплощением строгой математической, инженерной, технократической мысли, а в основе образовательного процесса лежат психолого-педагогические, во многом субъективные закономерности деятельности преподавателей и обучающихся, начиная с их мотивации и заканчивая интуиций и личностным смыслом передаваемой и получаемой информации.

Наибольшую трудность представляет переход от информации, циркулирующей в системе обучения, к самостоятельным практическим действиям и поступкам. Это классическая проблема применения знаний на практике, а на психологическом языке проблема перехода от мысли к действию. 
Многие исследователи отмечают, что при всё возрастающем уровне цифровизации общества и системы образования от человека требуется не владение необходимыми для жизни и профессиональной деятельности знаниями, а получение доступа к компьютерной системе, где находится нужная информация. Всё это приводит к деградации функций всех психических познавательных процессов: восприятия, памяти, мышления, речи, представления, воображения человека, а также внимания.

В отсутствие теории цифрового обучения его механическое встраивание в традиционное обучение только усиливает недостатки обоих. Так, П. Нортон (США) пишет, что обучающие системы на базе компьютера разрабатываются для традиционного обучения вместо того, чтобы обеспечивать на новой основе перспективные пути использования исключительных возможностей компьютера. Он является мощным средством оказания помощи в понимании людьми многих явлений и закономерностей, однако неизбежно порабощает ум, располагающий лишь набором заученных фактов и навыков [18].

Такое мощное средство, как компьютер, нельзя просто встроить в традиционную дидактическую систему и надеяться на повышение качества образования. Необходимо разработать адекватную психолого-педагогическую и собственно педагогическую теорию, органично включающую в себя компьютер как средство обучения с его действительно огромными возможностями получения, хранения, переработки и передачи информации.

Но такой общепризнанной теории, разработанной с учётом исторических, философских, психологических и собственно педагогических аспектов проблемы, как известно, в мире не существует, хотя есть масса исследований и защищённых диссертаций. Поэтому основания для всё более широкого использования цифровых технологий во многом носят не обоснованный наукой, внешний характер. Приводятся аргументы: так поступают в развитых странах; нужно кому-то продавать всю эту технику, так решило руководство образовательного учреждения или орган управления всем образованием, на это выделены средства и т.п. То есть встраивание цифровых средств в традиционную систему обучения во многом осуществляется по внешним причинам, а не потому, что получены веские научные основания продуктивности их использования [16].

Подчеркнем, что именно образование и воспитание, в первую очередь, являются национальной безопасностью и основополагающим достоянием страны.

Представляется, что в качестве научной основы, к которой может быть «привязана» цифровизация обучения, в наибольшей мере способна стать психолого-педагогическая теория контекстного образования, около 40 лет разрабатываемая в научно-педагогической школе Вербицкого Андрея Александровича.

Разделяем и считаем актуальной идею В.А. Плешакова о необходимости введения в учебный план школы специального практико-ориентированного курса, направленного на научно обоснованное (пока оно идет стихийно) компетентное владение подрастающим и уже подросшим поколением цифровыми устройствами в уже наступившую эпоху всеобщей киберсоциализации общества [8].

Остается актуальным на любой ступени обучения учить школьников и студентов думать, ответственно подходить к любой воспринимаемой информации и принимать верное решение, делать правильный выбор.

Трудно сказать, какими специалистами станут сегодняшние студенты; у них другая история жизни, другие интересы, взгляды, другой образ жизни. Понятно одно - безопасное, критичное, уверенное применение цифровых технологий в различных сферах жизнедеятельности и профессий является сегодня важнейшей компетенцией XXI века, которая требует такого же формирования, как и знания, умения, навыки, мотивация, ответственность.

Напомним, что главной целью высшего образования является развитие системного подхода к решению проблем и поставленных задач. А без сформированности всех операций мышления, критического и дивергентного мышления, нахождения причинно-следственных связей и противоречий тех или иных явлений, разработки нескольких вариантов решения 
задачи невозможно формирование системного мышления и, следовательно, системного подхода к решению проблем, целеполагания. Именно эти качества необходимы каждому выпускнику вуза.

$$
* * *
$$

1. Богословский В.И., Бусыгина А.Л., Аниськин В.Н. Концептуальные основы высшего образования в условиях цифровой экономики // Самарский научный вестник, 2019. Т.8. №1 (26) [Электронный ресурс] Режим доступа: https://cyberleninka.ru/article/n/kontseptualnye-osnovy-vysshego-obrazovaniya-v-usloviyahtsifrovoy-ekonomiki/viewer, свободный.

2. Бурцева Э.В., Чепак О.А., Куликова О.А. Некоторые результаты исследования влияния цифровых технологий на учебную деятельность студентов // Педагогика и просвещение. - 2020. - № 1.

3. Варламова Л.Д. Проблемы межличностных отношений студентов технического вуза в условиях цифровизации общества // Мир науки. Педагогика и психология, 2019 №6, https://mirnauki.com/PDF/90PDMN619.pdf (доступ свободный).

4. Вербицкий А.А. Цифровое обучение: проблемы, риски и перспективы / А.А. Вербицкий // Электронный научно-публицистический журнал "Ноmo Cyberus". - 2019. - №1(6). [Электронный ресурс] - Режим доступа: http://journal.homocyberus.ru/Verbitskiy_AA_1_2019, свободный. - Загл. с экрана.

5. Вербицкий, А.А. «Цифровое поколение: проблемы образования»// Профессиональное образование. Столица. - № 7. - 2016. - С. 10-13.

6. Вербицкий А.А. Теория и технологии контекстного образования. Учебное пособие. - М., МПГУ, 2017.

7. Воинова О.И., Плешаков В.А. Личность и киберсоциум: становление киберсоциальности и классификация людей по степени интегрированности в киберсоциум // Электронный научно-публицистический журнал «Homo Cyberus». - $\quad 2018$. $\quad$ - $\quad$ № $1(4)$ [Электронный pecypc]URL: http://journal.homocyberus.ru/personality_and_cybersocium_formation_of_cybersafty_and_classification_of_people _according_to_the_extent_of_the_integration_into_the_cybersocium.

8. Выготский Л.С. Собрание сочинений: В 6-ти т. Т.3 Проблемы развития психики / Под ред. А.М. Матюшкина. - М. Педагогика, 1983.

9. Каптерев П.Ф. Детская и педагогическая психология. - Москва: Московский психолого-социальный институт, 1999. - 336 с.

10. Кузьминов Я.И. ВШЭ полностью откажется от традиционных лекций в пользу онлайн-курсов [Электронный pecypc] URL: https://rb.ru/news/vshe-study-online

11. Нестик Т. Что делать социологам? Каково место социальных наук в осмыслении цифровизации и искусственного интеллекта? // Социодиггер. 2020. Октябрь. Том 1. Выпуск 3: Цифровизация и искусственный интеллект. - С. 33-37.

12. Петрова Н.П., Бондарева Г.А. Цифровизация и цифровые технологии в образовании // Мир науки, культуры, образования. - 2019. - №5 (78). - С. 353-355.

13. Рудской А.И., Боровков А.И., Романов П.И., Колосова О.В. Пути снижения рисков при построении в России цифровой экономики. Образовательный аспект // высшее образование в России. - 2019. - Т.28. №2. - С. 922.

14. Рыбакина Н.А. Компетентностно-контекстная модель обучения и воспитания в общеобразовательной школе // Образование и наука. - 2017. - Том 19. - № 2. - С. 31-50.

15. Стрекалова Н.Б. Риски внедрения цифровых технологий в образовании // Вестник Самарского университета. История, педагогика, филология. 2019. Т.25. №2. 84-88. DOI: http://doi.org/10.18287/2542-0445-2019-25-284.88.

16. Norton P. Computer Potential and Computer Educators: a Proactive View of Computer Education // Educational Technology - 1983. - Vol. 23. - № 10. - P. 25-28.

\section{Пашкова А.А., Галашова Е.С. \\ Особенности применения внеурочной деятельности по ОБЖ в средней общеобразовательной школе по данным анкетирования, проведенного на базе школы № 3 города Петрозаводска в 2021 году}

Петрозаводский государственный университет

(Россия, Петрозаводск)

doi: 10.18411/trnio-12-2021-241

Аннотация

В статье обобщена специфика применения внеурочной деятельности по ОБЖ в средней общеобразовательной школе по данным анкетирования, и приведены рекомендации по внедрению данного вида деятельности в учебный процесс. 